\title{
Influence of prednisolone on craniofacial and long bones in growing rats: A cephalometric and peripheral quantitative computed tomographic analysis
}

\author{
Yuko Fujita, Takahiro Nishioka, Takashi Kinjo and Kenshi Maki \\ Division of Developmental Stomatognathic Function Science, \\ Department of Growth and Development of Functions, Kyushu Dental College \\ 2-6-1 Manazuru, Kokurakita-ku, Kitakyushu 803-8580, JAPAN
}

\begin{abstract}
Glucocorticoids are used for treatment of a variety of diseases, although they are also known to have an effect on skeletal growth and induce osteoporosis. The aim of this study was to investigate whether exposure to prednisolone had an effect on craniofacial bone growth and the internal bone structure in young rats. Twenty 5-week-old growing male rats were divided into two equal groups. Prednisolone at $30 \mathrm{mg} / \mathrm{kg} /$ day (prednisolone group) or no drug (control group) was administered orally on alternate days for 6 weeks. Thereafter, growth of the total skull, neurocranium, maxilla, and mandible was determined on lateral cephalograms, while cortical bone density and strength strain index (SSI) of the femur diaphysis and mandible were determined using peripheral quantitative computed tomography (pQCT). In addition, the femur length was measured. In the prednisolone group, total body weight, femur length, mandibular corpus length and height, and coronoid process height were reduced. No effects of prednisolone administration on cortical bone density of the femur and mandible were detected, however, the SSI values, cortical bone cross-sectional area, and mineral content of the femur and mandible, and cortical thickness and periosteal circumference of the femur in the prednisolone group were significantly lower when compared with the control group. The findings indicate that glucocorticoid administration decreases longitudinal and mandibular bone growth, quality, and strength in growing rats, whereas it has no significant effect on cortical bone density.
\end{abstract}

\author{
Key words \\ Bone growth, \\ Craniofacial bone, \\ Femur, \\ Glucocorticoid, \\ Rats
}

\section{Introduction}

It is well known that long-term use and high doses of glucocorticoids, to treat autoimmune, collagen, chronic renal diseases, and asthma, can cause adverse skeletal changes such as osteoporosis and increase the risk of fracture ${ }^{1-3)}$. A few studies have demonstrated that glucocorticoid-induced systemic osteoporosis is correlated with mandibular bone loss in adult human patients ${ }^{3)}$ and aged rabbits ${ }^{4}$. Currently, many children are given glucocorticoids for a variety of diseases, although adverse effects on

Received on January 9, 2007

Accepted on August 23, 2007 bone mass and bone growth are often the result ${ }^{5-7)}$. In studies of growing rats it has been reported that high dose glucocorticoid administration decreases femoral bone mineral density ${ }^{8)}$ and suppresses longitudinal bone growth ${ }^{9}$. However, few studies have investigated the effects of glucocorticoids on mandibular and long bone tissue simultaneously during growth. On the other hand, craniofacial bone tissues, including the mandible, are formed by complicated processes of ossification, such as membranous, sutural, and cartilaginous growth ${ }^{10,11)}$, very few studies have been conducted regarding the influence of glucocorticoids on craniofacial bone growth. Thus, elucidation of the effects of glucocorticoidinduced skeletal osteoporosis on craniofacial bone 


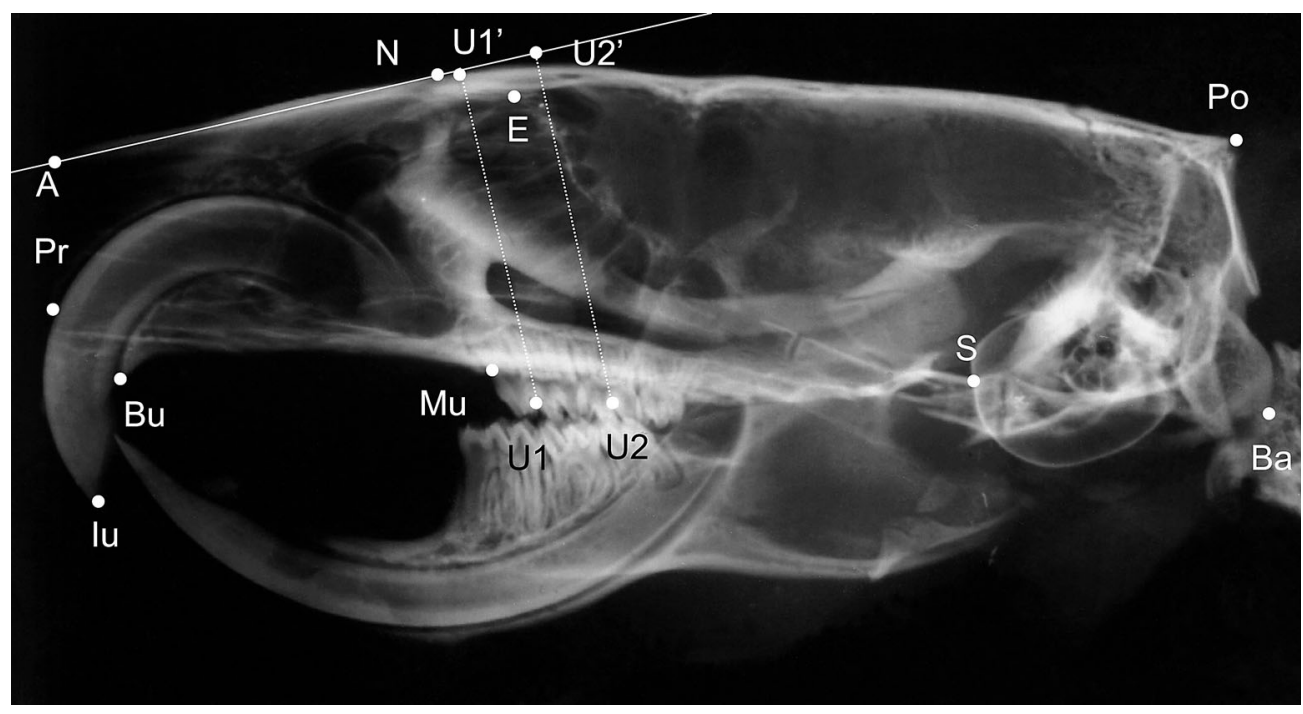

Fig. 1 Reference points and measurements on lateral cephalograms of the left craniofacial bone

Po: Most posterior point on the cranial vault, N: Point of the nasofrontal suture, A: most anterior point on the nasal bone, $\mathrm{E}$ : Intersection of the frontal bone and floor of the anterior cranial fossa, S: Intersection of the most anterior tympanic bulla and the superior border of the sphenoid bone, Ba: Most posterior and inferior point of occipital condyle, Pr: Most inferior and anterior point on the alveolar process of the premaxilla, Bu: Point on the premaxilla between the jaw bone and lingual surface of the upper incisors, $\mathrm{Mu}$ : Point on the intersection between the maxillary bone and the mesial surface of the upper first molar, Iu: Most prominent point between the incisal edges of the upper incisors, U1: Point on the mesial occlusal fossa of the upper first molar, U1': Crossing point on A-N perpendicular to A-N from U1, U2: Point on the distal occlusal fossa of the upper second molar, U2': Crossing point on A-N perpendicular to A-N from $\mathrm{U} 2$

tissue during childhood is important.

Recent clinical data have shown that glucocorticoid treatment has little or no effect on bone mineral density, although an increase in fracture risk has been reported ${ }^{12-14)}$. Bone strength is determined by bone quality such as bone geometry, trabecular micro-architecture, and cortical thickness as well as by bone density ${ }^{15}$, while quality, in particular, depends mainly on the cortical components ${ }^{16}$. The different responses found in previous studies may have been due to a decrease in cortical bone quality, however, the relationship between bone strength and bone quality following glucocorticoid treatment has not been clarified.

In the present study the effects of glucocorticoid administration on skeletal and craniofacial bone growth, mass, quality, and strength in growing rats was investigated.

\section{Materials and Methods}

\section{Experimental animals}

All animal procedures were approved by the Committee for Care and Use of Laboratory Animals of Kyushu Dental College (03.077). Twenty 5-week- old Wistar male rats, with an average body weight of $130 \pm 5 \mathrm{~g}$ were obtained from Seac Yoshitomi (Fukuoka, Japan) and housed individually in small cages under a 12-hour light-dark cycle, at a constant temperature of $22 \pm 1^{\circ} \mathrm{C}$ and humidity of $50 \pm 5$ per cent, and fed a standard diet (Oriental Yeast, Tokyo, Japan) containing $500 \mathrm{mg} / 100 \mathrm{~g}$ calcium and distilled water ad libitum.

\section{Experimental design}

The rats were randomly divided into two equal groups of 10 and treated for 6 weeks. The experimental group was given prednisolone sodium succinate (Shionogi \& Co., Ltd., Osaka, Japan) orally at $30 \mathrm{mg} / \mathrm{kg} /$ day on alternate days, while the control group was given orally distilled water on alternate days. The dosage of prednisolone sodium succinate was based on results of a previous study that showed $30 \mathrm{mg} / \mathrm{kg}$ /day produced an increase in bone resorption and decrease in bone mass ${ }^{17}$. At the end of the experimental period, all rats were deeply anaesthetized with diethyl ether and given a lethal injection of thiamylal natrium (Isozole; Mitsubishi Pharma Co., Osaka, Japan) intraperitoneally. Thereafter, the femurs and heads were removed and fixed 


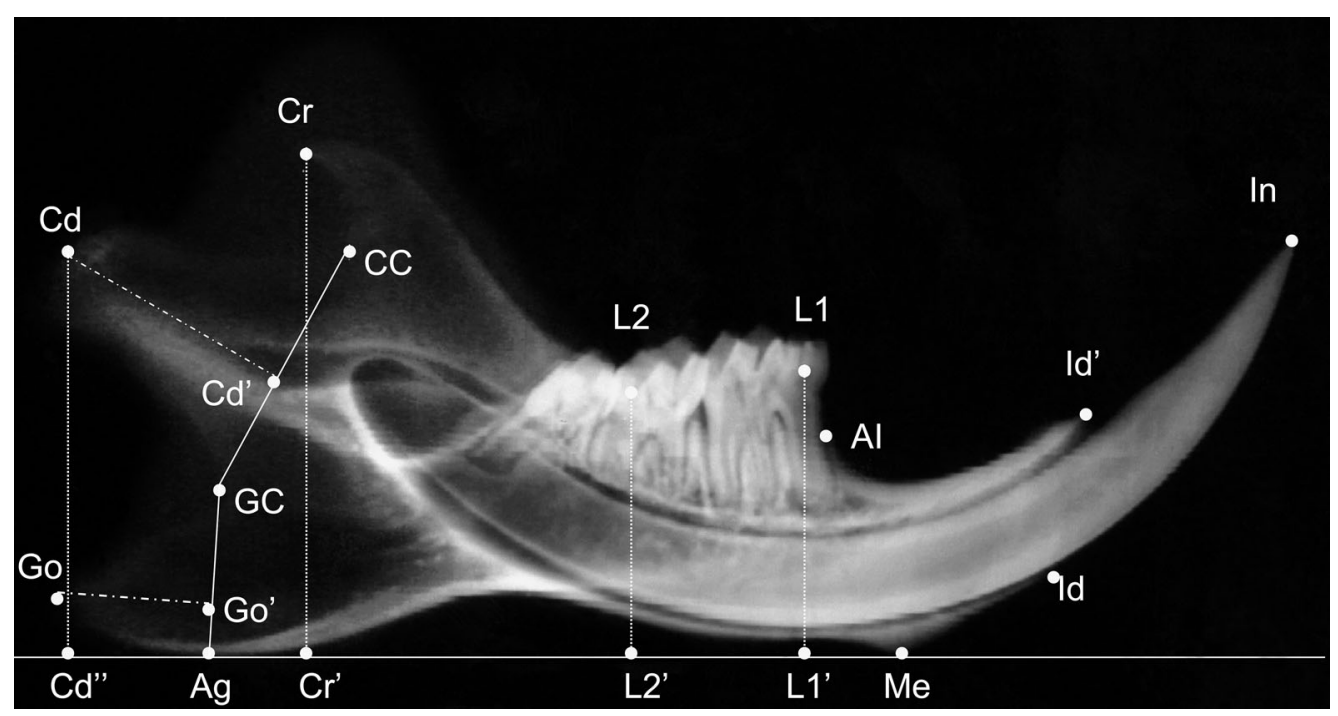

Fig. 2 Reference points and measurements on lateral cephalograms of the right mandible

Me: Menton, Ag: Antegonion, Go: Gonion, Go’: Crossing point on GC-Ag perpendicular to GC-Ag from Go, GC: The deepest point of the line Go-Cd, CC: The most distant point of the line Cd-Cr, Cd: The most posterior point of the condylar head, Cd': Crossing point on CC-GC perpendicular to CC-GC from Cd, Cd' ': Crossing point on Me-Ag perpendicular to Me-Ag from Cd, Cr: The most posterior point of the coronoid process, $\mathrm{Cr}$ ': Crossing point on $\mathrm{Me}-\mathrm{Ag}$ perpendicular to $\mathrm{Me}-\mathrm{Ag}$ from $\mathrm{Cr}$, Id: Infradentale (labial side), Id': Infradentale (lingual side), AI: The highest point of the mesial alveolar bone at the lower first molar, In: Most prominent point of the lower incisor, L1: Point on the mesial occlusal fossa of the lower first molar, L1': Crossing point on Me-Ag perpendicular to Me-Ag from L1, L2: Point on the distal occlusal fossa of the lower second molar, L2': Crossing point on Me-Ag perpendicular to $\mathrm{Me}-\mathrm{Ag}$ from L2

with a 10 per cent neutral buffered formalin solution.

\section{Body weight and skeletal length}

Total body weight was measured at various time points throughout the experimental period. The femur length was determined by direct measurements using a calliper with an accuracy of $0.01 \mathrm{~mm}$.

\section{Lateral cephalometric analysis of craniofacial skeleton}

Lateral cephalograms were taken of all the rats using an ESM-2 (Softex Co., Tokyo, Japan). After fixation, the cranial bones were cut laterally along the median suture from the parietal bone to the mandible. The median sagittal face of the head was then mounted to contact the film surface. The cephalogram was taken with dental occlusal film (FG, Fuji Film, Tokyo, Japan) under an electric condition of $30 \mathrm{kV}$ and $5 \mathrm{~mA}$ with an exposure time of 90 seconds.

After obtaining cephalograms of the skull, the mandible was extracted and the soft tissue around the alveolar part of the mandible was carefully detached to expose the mental foramen. The median sagittal face of the mandible was then mounted to contact the film surface, with the mental foramen set immediately under the focus, and the cephalogram was taken under an electric condition of $28 \mathrm{kV}$ and $6 \mathrm{~mA}$ for 60 seconds.

Cephalometric analysis was performed according to the modified method of Kiliaridis et al. ${ }^{18)}$ The standard length of wire $(10 \mathrm{~mm})$ was attached to each film and reproduced on the X-ray film. The developed radiographic images were enlarged 5 times and printed on photographic paper, after which the points for determination were traced. The measurements were calibrated according to the image of the standard length of the wire employing a calliper with an accuracy of $0.01 \mathrm{~mm}$. Accordingly, the results were 5 times greater than the actual length. The regions of the craniofacial bone and mandible corresponding to the skeletal units, as described by Kiliaridis et al. ${ }^{18)}$, Vandeberg et al. ${ }^{19)}$, Maki et al. ${ }^{20)}$ and Nonaka et al. ${ }^{21)}$ were modified. Figures 1 and 2 depict the landmarks and measurement items for the craniofacial bone and mandible, respectively.

\section{Error of the method}

The methodological procedure of cephalometric analysis was repeated in each 10 of craniofacial 
Table 1 Error measurements for the linear cephalometric characteristics

\begin{tabular}{llll}
\hline & $\begin{array}{c}\text { Error of measurements } \\
(\mathrm{mm})\end{array}$ & & $\begin{array}{c}\text { Error of measurements } \\
(\mathrm{mm})\end{array}$ \\
\hline $\begin{array}{c}\text { Total skull } \\
\text { Po-A }\end{array}$ & 0.88 & $\begin{array}{c}\text { Mandible } \\
\text { Me-Go }\end{array}$ & 0.57 \\
Ba-Pr & 1.08 & $\begin{array}{c}\text { Me-Ag } \\
\text { Cd-Cd' }\end{array}$ & 0.74 \\
Neurocranium & & Go-Go' & 0.78 \\
Po-E & 1.30 & Al-Id' & 0.66 \\
Ba-S & 0.24 & CC-GC & 0.73 \\
S-E & 0.97 & GC-Ag & 0.61 \\
Po-Ba & 0.95 & Cr-Cr' & 0.42 \\
Maxilla & & Cd-Cd', & 0.53 \\
N-A & 0.55 & Cd-Go & 0.58 \\
E-A & 0.68 & Cd-Ag & 0.51 \\
Mu-Bu & 0.73 & In-Id & 0.61 \\
Mu-Pr & 0.73 & In-Id' & 0.58 \\
A-Bu & 0.35 & L1-L1' & 0.45 \\
N-Mu & 0.50 & L2-L2' & 0.35 \\
Iu-A & 0.53 & & 0.32 \\
Iu-Pr & 0.16 & & \\
Iu-Bu & 0.19 & & \\
U1-U1 & 0.35 & & \\
U2-U2' & 0.58 & & \\
\hline
\end{tabular}

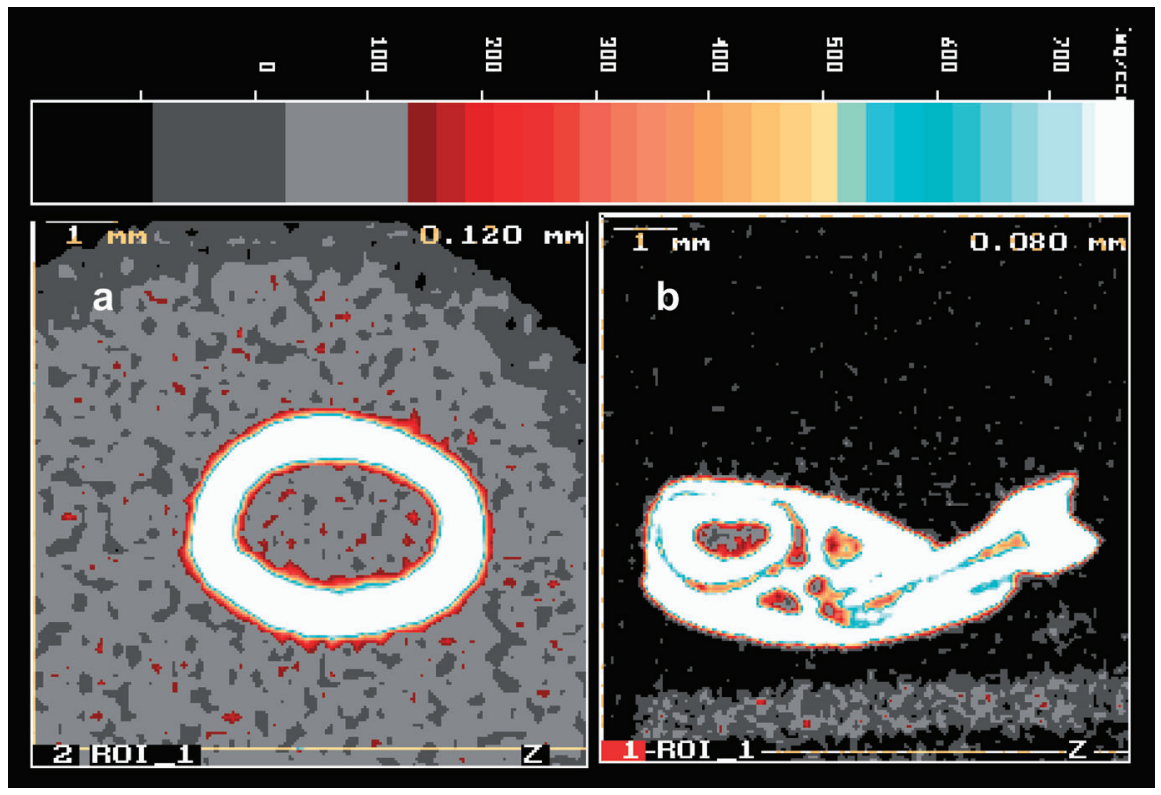

Fig. 3 Peripheral quantitative computed tomography scans of Wistar rat specimens A femur diaphysis specimen is shown on the left (a), and a mandibular bone specimen on the right (b).

and mandibular bones 2 weeks after the initial measurements. The error of the method was calculated according to the formula of Dahlberg ${ }^{22)}$ : $\mathrm{Se}=\sqrt{\sum \mathrm{d}^{2} / 2 \mathrm{n}}$, where $\sum \mathrm{d}^{2}$ is the sum of the squared differences between pairs of recordings and $n$ is the number of duplicate measurements. Its range was found to be from $0.16 \mathrm{~mm}$ to $1.30 \mathrm{~mm}$ (Table 1). 
Table 2 Changes in the body weight and length of the femurs

\begin{tabular}{lcclll}
\hline & \multicolumn{2}{c}{ Body weight } & & Skeletal length \\
\cline { 1 - 3 } & Initial $(\mathrm{g})$ & Final $(\mathrm{g})$ & & Femur $(\mathrm{mm})$ \\
\hline Control group $(\mathrm{n}=10)$ & $136.96 \pm 7.07$ & $387.48 \pm 19.70$ & & $37.75 \pm 0.34$ \\
Prednisolone group $(\mathrm{n}=10)$ & $132.48 \pm 4.60$ & $282.72 \pm 10.18 * *$ & & $35.49 \pm 0.32 * *$ \\
\hline
\end{tabular}

Data are given as mean $\pm \mathrm{SD}$. Compared with the control group. $* *: P<0.01$

Table 3 Linear measurements of the craniofacial skeleton

$(\mathrm{mm})$

\begin{tabular}{lcc}
\hline & $\begin{array}{c}\text { Control group } \\
(\mathrm{n}=10)\end{array}$ & $\begin{array}{c}\text { Prednisolone group } \\
(\mathrm{n}=10)\end{array}$ \\
\hline $\begin{array}{c}\text { Total skull } \\
\text { Po-A }\end{array}$ & $156.65 \pm 0.74$ & $156.20 \pm 0.65$ \\
Ba-Pr & $154.71 \pm 3.50$ & $152.97 \pm 2.37$ \\
Neurocranium & & \\
Po-E & $91.26 \pm 2.55$ & $89.88 \pm 2.11$ \\
Ba-S & $39.62 \pm 0.94$ & $39.95 \pm 1.16$ \\
S-E & $66.06 \pm 2.54$ & $63.75 \pm 1.55$ \\
Po-Ba & $36.43 \pm 1.92$ & $36.18 \pm 2.39$ \\
Maxilla & & \\
N-A & $56.42 \pm 1.38$ & $55.12 \pm 1.40$ \\
E-A & $66.70 \pm 1.46$ & $66.81 \pm 2.94$ \\
Mu-Bu & $45.41 \pm 2.07$ & $43.83 \pm 0.36$ \\
Mu-Pr & $53.76 \pm 3.38$ & $52.99 \pm 1.01$ \\
A-Bu & $28.06 \pm 1.98$ & $28.62 \pm 2.75$ \\
N-Mu & $38.71 \pm 1.49$ & $37.32 \pm 0.93$ \\
Iu-A & $42.03 \pm 2.36$ & $43.49 \pm 2.73$ \\
Iu-Pr & $26.87 \pm 1.39$ & $26.97 \pm 2.24$ \\
Iu-Bu & $17.08 \pm 0.46$ & $16.73 \pm 0.54$ \\
U1-U1 & $42.72 \pm 2.01$ & $41.82 \pm 1.22$ \\
U2-U2 & $46.42 \pm 2.20$ & $45.38 \pm 1.31$ \\
\hline
\end{tabular}

Data are given as mean \pm SD.

\section{Peripheral quantitative computed tomography (pQCT) measurements}

For three-dimensional peripheral quantitative computed tomography (pQCT) measurements, an XCT Research SA + series (Stratec, Medizintechnik, Pforzheim, Germany) was employed. The right femur diaphysis was used to measure cortical bone density, cross-sectional area, mineral content, thickness, and periosteal and endosteal circumference. Each femur diaphysis, which contains mostly cortical bone, was scanned at a point $13.0 \mathrm{~mm}$ from the distal growth plate, and measured with a voxel size of $0.12 \mathrm{~mm}$ and height of $0.46 \mathrm{~mm}$ (Fig. 3a).
Table 4 Linear measurements of the mandible

\begin{tabular}{lcc} 
& \multicolumn{2}{c}{$(\mathrm{mm})$} \\
\hline & $\begin{array}{c}\text { Control group } \\
(\mathrm{n}=10)\end{array}$ & $\begin{array}{c}\text { Prednisolone group } \\
(\mathrm{n}=10)\end{array}$ \\
\hline Mandible & & \\
Me-Go & $105.79 \pm 5.81$ & $97.48 \pm 1.46^{* *}$ \\
Me-Ag & $87.35 \pm 2.42$ & $84.23 \pm 2.44$ \\
Cd-Cd' & $26.05 \pm 2.90$ & $24.88 \pm 2.19$ \\
Go-Go' & $17.26 \pm 2.99$ & $12.65 \pm 1.38^{* *}$ \\
Al-Id' & $34.53 \pm 1.89$ & $31.70 \pm 1.38$ \\
CC-GC & $36.18 \pm 2.74$ & $35.33 \pm 2.29$ \\
GC-Ag & $23.53 \pm 2.10$ & $21.55 \pm 2.14$ \\
Cr-Cr' & $66.54 \pm 0.95$ & $60.48 \pm 2.59^{*}$ \\
Cd-Cd', & $46.20 \pm 2.85$ & $45.83 \pm 2.57$ \\
Cd-Go & $32.39 \pm 3.51$ & $37.19 \pm 4.05$ \\
Cd-Ag & $49.05 \pm 2.38$ & $47.37 \pm 1.89$ \\
In-Id & $50.63 \pm 2.73$ & $50.98 \pm 3.03$ \\
In-Id' & $33.17 \pm 1.32$ & $34.38 \pm 2.12$ \\
L1-L1' & $35.05 \pm 1.20$ & $33.03 \pm 0.73^{*}$ \\
L2-L2' & $31.16 \pm 1.74$ & $30.79 \pm 1.12$ \\
\hline
\end{tabular}

Data are given as mean \pm SD. Compared with the control group. $*: P<0.05, * *: P<0.01$

The cortical region was determined after setting a threshold value of $690 \mathrm{mg} / \mathrm{cm}^{3}$. The right mandibular bone was used to measure cortical bone density, cross-sectional area, and mineral content. For those measurements, the centre of the mandibular first molar mesial root at three different positions with an interval of $0.1 \mathrm{~mm}$ was scanned, and the cortical component was measured using a voxel size of $0.08 \mathrm{~mm}$ and height of $0.26 \mathrm{~mm}$ (Fig. 3b). The cortical region was also defined by setting a threshold value of $690 \mathrm{mg} / \mathrm{cm}^{3}{ }^{23)}$.

\section{Bone strength (non-invasive assessment)}

Using pQCT for non-invasive assessment of mechanical properties, the bone strength of the femur diaphysis and mandible was evaluated to determine a strength strain index (SSI), with a threshold of 
Table 5 Cortical bone mineral parameters of the femur and mandible as measured using peripheral quantitative computed tomography

\begin{tabular}{|c|c|c|c|c|c|c|}
\hline & $\begin{array}{c}\text { Bone density } \\
\left(\mathrm{mg} / \mathrm{mm}^{3}\right)\end{array}$ & $\begin{array}{l}\text { Cross-sectional } \\
\text { area }\left(\mathrm{mm}^{2}\right)\end{array}$ & $\begin{array}{c}\text { Bone mineral } \\
\text { content } \\
(\mathrm{mg} / \mathrm{mm})\end{array}$ & $\begin{array}{l}\text { Thickness } \\
\text { (mm) }\end{array}$ & $\begin{array}{c}\text { Periosteal } \\
\text { circumference } \\
(\mathrm{mm})\end{array}$ & $\begin{array}{c}\text { Endosteal } \\
\text { circumference } \\
(\mathrm{mm})\end{array}$ \\
\hline \multicolumn{7}{|l|}{ Femur } \\
\hline Control group & $1,249.18 \pm 15.13$ & $6.11 \pm 0.13$ & $7.63 \pm 0.22$ & $0.83 \pm 0.03$ & $11.69 \pm 0.47$ & $6.96 \pm 0.45$ \\
\hline Prednisolone group & $1,250.54 \pm 15.54$ & $4.99 \pm 0.16^{* *}$ & $6.24 \pm 0.19 * *$ & $0.74 \pm 0.27 * *$ & $10.73 \pm 0.25^{* *}$ & $6.60 \pm 0.29$ \\
\hline \multicolumn{7}{|l|}{ Mandible } \\
\hline Control group & $1,238.69 \pm 10.21$ & $4.67 \pm 0.32$ & $5.79 \pm 0.39$ & - & - & - \\
\hline Prednisolone group & $1,231.12 \pm 15.71$ & $3.79 \pm 0.38 * *$ & $4.67 \pm 0.46^{* *}$ & - & - & - \\
\hline
\end{tabular}

Data are given as mean \pm SD. Compared with the control group. **: $P<0.01$

Table 6 Strength strain index (SSI) of the femur and mandible

\begin{tabular}{llll}
\hline & \multicolumn{1}{c}{ xSSI } & \multicolumn{1}{c}{ ySSI } & \multicolumn{1}{c}{ pSSI } \\
\hline Femur & & & \\
Control group & $3.81 \pm 0.17$ & $4.99 \pm 0.22$ & $7.52 \pm 0.39$ \\
Prednisolone group & $3.09 \pm 0.19^{* *}$ & $3.82 \pm 0.18^{* *}$ & $5.85 \pm 0.33^{* *}$ \\
& & & \\
Mandible & & $3.57 \pm 0.25$ & $4.53 \pm 0.36$ \\
Control group & $2.15 \pm 0.25$ & $2.64 \pm 0.32^{* *}$ & $3.31 \pm 0.39^{* *}$ \\
Prednisolone group & $1.64 \pm 0.26^{* *}$ & 2.01 \\
\hline
\end{tabular}

Data are given as mean $\pm \mathrm{SD}$. Compared with the control group. $* *: P<0.01$

xSSI: strength strain index for the reference axis x, ySSI: strength strain index for the

reference axis y, pSSI: strength strain index for the reference axis $\mathrm{z}$

$690 \mathrm{mg} / \mathrm{cm}^{3}$. SSI was calculated using the equation $\mathrm{SSI}=\mathrm{CBD} \cdot \mathrm{Z} / \mathrm{NCBD}$, where $\mathrm{CBD}$ is cortical bone density $\left(\mathrm{mg} / \mathrm{cm}^{3}\right), \mathrm{Z}$ is the section modulus $\left(\mathrm{mm}^{3}\right)$, and NCBD is the normal physiological value of cortical bone density $\left(1,200 \mathrm{mg} / \mathrm{cm}^{3}\right)^{23}$.

\section{Statistical analysis}

The distribution of variables is given as the mean \pm the standard deviation. A Mann-Whitney nonparametric $U$ test was used to compare the prednisolone and control group. A two-tailed $P$ value of $<0.05$ was considered statistically significant.

\section{Results}

\section{Body weight and skeletal growth}

The average body weight in each group and the length of the femur are shown in Table 2. The final body weight in the prednisolone group was significantly lower than that in the control group $(P<0.01)$. The total length of the femur in the prednisolone group was significantly shorter than those in the control group $(P<0.01)$.

\section{Lateral cephalometric analysis}

The results for total skull, neurocranium, and maxilla sizes are shown in Table 3. No significant differences were found between the prednisolone and control groups. For mandibular size (Table 4) the distances, Me-Go, Go-Go', Cr-Cr', and L1-L1', in the prednisolone group were significantly smaller than those in the control group $(P<0.01, P<0.01$, $P<0.05$, and $P<0.05$, respectively).

\section{Bone mineral status as determined by pQCT}

The results for cortical bone parameters of the femur and mandible are summarized in Table 5. No significant differences in cortical bone density of the femur and mandible or endosteal circumference of the femur were found between the two groups. In contrast, values for cortical bone cross-sectional area, mineral content of the femur and mandible, and 
cortical bone thickness and periosteal circumference of the femur in the prednisolone group were significantly lower $(P<0.01)$.

\section{Bone strength (non-invasive)}

SSI for the reference axes x (xSSI), y (ySSI) and z (pSSI) are summarized in Table 6. All values for the femur diaphysis and mandible in the prednisolone group were significantly lower than those in the control group $(P<0.01)$.

\section{Discussion}

In the present study of growing rats, reduced growth and advanced bone debility due to prednisolone treatment were observed in femoral osseous tissues, as well as in the mandible, whereas there was no apparent change in cortical bone density of the mandible and femur diaphysis. A number of studies have reported the mechanism of glucocorticoidinduced bone fragility, however, the issue has not been fully elucidated. Generally from 70 to 100 per cent of prednisolone administrated orally is absorbed in gut, which acts on target tissue cells mediating bloodstream ${ }^{24,25)}$. In a previous in vitro study, glucocorticoids were shown to cause an increase in osteoblast and osteocyte apoptosis and a decrease in osteoblast differentiation in mice ${ }^{26)}$. Further, Iu et al. ${ }^{27)}$ reported that glucocorticoids suppressed alkaline phosphatase (ALP) activity and type I collagen expression, as a result of which there was an inhibition of bone formation in rats. Hofbauer et al. ${ }^{28)}$ also found that glucocorticoid administration increased osteoclast activity and resulted in increased bone resorption in humans.

In the present study, $30 \mathrm{mg} / \mathrm{kg} /$ day of prednisolone was used. The minimum dose in a previous investigation, in which oral prednisolone enhanced bone resorption, ranged from $30 \mathrm{mg} / \mathrm{kg}$ to $100 \mathrm{mg} / \mathrm{kg}^{17)}$, although this is substantially higher than the dose used in clinical practice. In the present research it was found that total body weight and femur length in the prednisolone group were significantly lower than those in the control group, suggesting that the dose used caused a reduction in somatic growth.

Cephalometric analysis showed that although total skull, neurocranium, and maxilla sizes in the prednisolone group were not significantly different from those in the control group, the means values of these sizes in the prednisolone group were tended to be lower than those in the control group. It has previously been reported that growth of the calvaria and cranial base is achieve 2 and 5 weeks after birth, respectively, in rats, while the growth pattern of the neurocranium is classified as neural and closely related to enlargement of the brain ${ }^{29}$. Growth of the maxilla is mainly determined by the sutures, composed of fibrous connective tissue between the membranous craniofacial bones, which grow most actively during the pre- to neonatal period in small animals $^{30,31)}$. A longitudinal study of craniofacial growth using a growing rat model found that changes in the neurocranium and maxilla were small after 5 weeks, while growth of the mandible reached its maximum at 8 weeks ${ }^{32}$. In the present study, in which 5-week-old rats were used, it was concluded that prednisolone tended to suppress skull, neurocranium, or maxillary growth but it was not significantly different from that in the control group because in those bones their growth was nearly complete.

On the other hand, prednisolone administration led to growth reduction in the mandibular bone size according to several parameters. Although the reductions in other parameters were not statistically significant, their means values except for Cd-Go, In-Id and In-Id' tended to be lower than those in the control group. A previous study reported that excess glucocorticoid treatment in growing rats reduced mandibular corpus length and coronoid process height ${ }^{33)}$. The present results showed that the distances Me-Go, Go-Go', Cr-Cr', and L1-L1' in the prednisolone group were significantly shorter than those in the control group, suggesting that prednisolone reduces growth of the posterior corpus length (Me-Go, Go-Go'), coronoid process height (Cr-Cr'), and corpus height at the first molar (L1-L1').

Mandibular condyle development occurs in the growth plate by endochondral ossification as well as by longitudinal bone growth ${ }^{34)}$. Glucocorticoids are known to have direct effects on chondrocytes and osteoblasts, and alter the major regulators of cartilage growth, such as growth hormone and insulin-like growth factor I, which results in the suppression of linear growth in children and experimental animals ${ }^{35-37)}$. In the present study, femur length in the prednisolone group was significantly shorter than those in the control group, however, differences in condylar length (Cd-Cd') and height (Cd-Cd" and Cd-Go) were not significantly different between the two groups. In an histological study ${ }^{38)}$ in 
which the tibia metaphysis and mandibular condyle in growing rats given excess glucocorticoids were compared found a greater suppressive effect on the tibia, as the source of new cartilage cells in the tibia is mitosis of chondroblasts, while that of new cartilage cells in the mandibular condyle is the fibrous covering of the hyaline cartilage, the chondroblasts originating there from fibroblasts, with the result that the cartilages in these two sites are considered to have different embryonic origins and different modes of growth. Further, Delatte et al. ${ }^{39)}$ reported that cartilage of mandibular condyle appears to be more sensitive to IGF-I than that of the femoral head in young rats which may be due to the different developmental stage in vitro.

Furthermore, several researchers demonstrated that functional factors such as masticatory function rather than hormonal factors play a major role in mandibular condylar growth regulation, while longitudinal bone growth is regulated by only hormonal factors in growing rats ${ }^{40,41}$. These observations could suggest that the extensive effects of growth factors including IGF-I and functional stimulus on the mandibular condyle are superior to a suppressive effect of prednisolone, resulting in an absence of suppression in growth of mandibular condyle. Therefore, it was considered that the differential responses of cartilage in the femoral head and mandibular condyle to prednisolone may be because these two types of cartilages have differential embryonic origins, modes of growth, and are regulated differential functions.

Thus, in the present study it was concluded that prednisolone inhibited growth of long bone, but did not has an apparent suppressive effect on the growth of craniofacial bone, except for mandibular membranous ossification portions.

pQCT is used to measure bone density and calculate geometric values, and then determine noninvasive bone strength from cortical bone density and the modulus of the section. Ferretti et al. ${ }^{42)}$ compared non-invasive SSI determined by pQCT measurements and bending tests in rat femurs, and found a high correlation, demonstrating that the noninvasive SSI provided by pQCT could be used as an indicator of bone strength. In the present study, not only bone growth and bone density were considered, but also cortical bone quality and strength. The femur diaphysis and mandibular body, which both contain rich cortical bone, were selected in order to perform more accurate analyses of bone quality and strength. It is generally accepted that long-term and high dose glucocorticoid therapy decreases bone mineral density in the lumber, femur, tibia, and mandibular bones in both humans ${ }^{1-3,5,43)}$ and animals ${ }^{4,8,44)}$, however, in the present results although in the mandible the mean value of cortical bone density in the prednisolone group was tended to be lower than that in the control group, in the femur and mandible no significant differences were found between the two groups, showing that the present results were different from those of previous studies. These data indicated that prednisolone exposure does not have a significant effect on bone mineralization. Dempster et $a l .{ }^{45}$ ) suggested that the lack of change in bone mineralization could be because glucocorticoids increase osteoclast apoptosis in rats and thereby counterbalance the effect of glucocorticoids on osteoblast apoptosis in vitro, which is in sharp contrast to the effects on human bone tissue. However, in recent clinical reports, young adult patients treated with a glucocorticoid demonstrated an increased risk of vertebral fracture, although there was little or no effect on bone mineral density ${ }^{12-14)}$. Therefore, it is considered that the major action of glucocorticoids is a reduction in bone strength rather than a decrease in bone mineralization in both humans and animals.

In the present research, all SSI parameters for both the femur and mandible in the prednisolone group were significantly lower than those in the control group, suggesting that prednisolone treatment caused a decrease in bone strength in both the femur and mandible. In addition, the values for cortical bone cross-sectional area, mineral content in the mandible and femur, and cortical bone thickness and periosteal circumference of the femur in the prednisolone group were significantly lower than those in the control group, while the difference in endosteal circumference value was not significant. These observations suggest that prednisolone suppressed membranous ossification by reducing the rate of bone formation on the periosteal surface and decreases cortical bone quality in the femur.

In mandible the results of cephalometric analysis indicated that prednisolone suppressed membranous ossification. Further, Wang et al. ${ }^{44)}$ also reported that the excess glucocorticoid reduced the rate of bone formation of cortical bone of the mandibular body in rats. Therefore, we considered that the mechanism of growth suppression of membranous ossification potions in the mandible is similar to that in the 
femoral diaphysis. Thus, it was demonstrated that prednisolone has an effect on bone geometry by inhibiting periosteal bone formation which results in decreased bone strength without affecting bone mineralization both in the femur and mandible.

Dual energy X-ray absorptiometry (DXA) is useful for prediction and is the standard method for measurement of two-dimensional bone mineral density of glucocorticoid-induced fracture risk ${ }^{46)}$. On the other hand, from $\mathrm{pQCT}$ analysis results, it was found that cortical bone quality and bone strength were decreased by prednisolone exposure, whereas bone density was unaffected. Therefore, it was concluded that SSI values obtained by pQCT are more useful than DXA findings for prediction of glucocorticoid-induced fracture risk.

In the recent report judicious use of glucocorticoid therapy coupled with improved nutrition and promotion of weight bearing activities, in addition calcium and vitamin D supplementation are recommended to children who will initiate glucocorticoid therapy although there is little objective clinical evidence to suggest that these practices prevent glucocorticoid-induced growth retardation and adverse bone health ${ }^{47)}$. Currently the anti-resorptive drugs, bisphosphonates therapy is widely used in adults with glucocorticoid-induced osteoporosis ${ }^{48,49)}$, but need to be carefully evaluated in the pediatric setting ${ }^{50)}$.

Thus, we could not speculate regarding the mechanism involved with the lack of change in cortical bone density, although bone debility was clearly caused by prednisolone administration. Further, no evidence has been presented that bisphosphonates are effective in glucocorticoidinduced bone debility during growing phase. In future we hope to examine the ossification mechanism of in vitro and the efficacy of bisphosphonates therapy.

Furthermore, in the present study, 5-week-old rats were treated for 6 weeks to investigate bone growth and cortical bone tissue changes. Future research will focus on the complex effects and mechanisms of glucocorticoids on bone tissue, as they are likely to be dependent on species and age, as well as duration and time of exposure.

\section{Conclusions}

The results showed the suppressive effects of glucocorticoid administration on bone growth, and quality and strength of cortical bone tissues in the mandible and femur, while cortical bone density were not affected. It is important to be aware of mandibular growth retardation and bone debility in children receiving glucocorticoid therapy. Further, glucocorticoid-induced fracture risk should be determined by not only bone mineral density, but also bone quality.

\section{Acknowledgments}

The authors wish to thank Mr. Kiichi Nonaka (Elk Corporation Research Laboratory) for his helpful advice and co-operation with this study.

\section{References}

1) Tsugeno, H., Goto, B., Fujita, T., Okamoto, M., Mifune, T., Mitsunobu, F., Ashida, K., Hosaki, Y., Tsuji, T. and Tanizaki, Y.: Oral glucocorticoidinduced fall in cortical bone volume and density in postmenopausal asthmatic patients. Osteoporosis Int 12: 266-270, 2001.

2) Jardinet, D., Lefebvre, C., Depresseux, G., Lambert, M., Devogelaer, J.P. and Houssiau, F.A.: Longitudinal analysis of bone mineral density in premenopausal female systemic lupus erythematosus patients: deleterious role of glucocorticoid therapy at the lumber spine. Reumatology (Oxford) 39: 389-392, 2000.

3) Olgaard, K., Storm, T., van Wowern, N., Daugaard, H., Egfjord, M., Lewin, E. and Brandi, L.: Glucocorticoid-induced osteoporosis in the lumber spine, forearm, and mandible of nephrotic patients: a double-blind study on the high-dose, long-term effects of prednisone versus deflazacort. Calcif Tissue Int 50: 490-497, 1992.

4) Southard, T.E., Southard, K.A., Krizan, K.E., Hillis, S.L., Haller, J.W., Keller, J. and Vannier, M.W.: Mandibular bone density and fractal dimension in rabbits with induced osteoporosis. Oral Surg Oral Med Oral Pathol Oral Radiol Endod 89: 244-249, 2000.

5) Simon, D., Lucidarme, N., Prieur, A.M., Ruiz, J.C. and Czernichow, P.: Effects on growth and body composition of growth hormone treatment in children with juvenile idiopathic arthritis requiring steroid therapy. J Rheumatol 30: 2492-2499, 2003.

6) Boot, A.M., de Jongste, J.C., Verberne, A.A., Pols, H.A. and de Muinck Keizer-Schrama, S.M.: Bone mineral density and bone metabolism of prepubertal children with asthma after long-term treatment with inhaled corticosteroids. Pediatr Pulmonol 24: 379384, 1997.

7) Avioli, L.V.: Glucocorticoid effects on statural growth. Br J Rheumatol 32(Suppl 2): 27-30, 1993.

8) Pennisi, P., D’Alcamo, M.A., Leonetti, C., Clementi, A., Cutuli, V.M., Riccobene, S., Parisi, N. and 
Fiore, C.E.: Supplementation of L-arginine prevents glucocorticoid-induced reduction of bone growth and bone turnover abnormalities in a growing rat model. J Bone Miner Metab 23: 134-139, 2005.

9) Ortoft, G., Andreassen, T.T. and Oxlund, H.: Growth hormone increases cortical and cancellous bone mass in young growing rats with glucocorticoid-induced osteopenia. J Bone Miner Res 14: 710-721, 1999.

10) Opperman, L.A.: Cranial sutures as intramembranous bone growth sites. Dev Dyn 219: 472-485, 2000.

11) Lee, S.K., Kim, Y.S., Oh, H.S., Yang, K.H., Kim, E.C. and Chi, J.G.: Prenatal development of the human mandible. Anat Rec 263: 314-325, 2001.

12) Kumagai, S., Kawano, S., Atsumi, T., Inokuma, S., Okada, Y., Kanai, Y., Kaburaki, J., Kameda, H., Suwa, A., Hagiyama, H., Hirohata, S., Makino, H. and Hashimoto, H.: Vertebral fracture and bone mineral density in women receiving high dose glucocorticoids for treatment of autoimmune diseases. J Rheumatol 32: 863-869, 2005.

13) Van Staa, T.P., Laan, R.F., Barton, I.P., Cohen, S., Reid, D.M. and Cooper, C.: Bone density threshold and other predictors of vertebral fracture in patients receiving oral glucocorticoid therapy. Arthritis Rheum 48: 3224-3229, 2003.

14) Walsh, L.J., Lewis, S.A., Wong, C.A., Cooper, S., Oborne, J., Cawte, S.A., Harrison, T., Green, D.J., Pringle, M., Hubbard, R. and Tattersfield, A.E.: The impact of oral corticosteroid use on bone mineral density and vertebral fracture. Am J Respir Crit Care Med 166: 691-695, 2002.

15) Ammann, P. and Rizzoli, R.: Bone strength and its determinants. Osteoporosis Int 14(Suppl 3): 13-18, 2003.

16) Ito, M., Nishida, A., Koga, A., Ikeda, S., Shiraishi, A., Uetani, M., Hayashi, K. and Nakamura, T.: Contribution of trabecular and cortical components to the mechanical properties of bone and their regulating parameters. Bone 31: 351-358, 2002.

17) Hara, K., Kobayashi, M. and Akiyama, Y.: Vitamin K2 (menatetrenone) inhibits bone loss induced by prednisolone partly through enhancement of bone formation in rats. Bone 31: 575-581, 2002.

18) Kiliaridis, S., Engström, C. and Thilander, B.: The relationship between masticatory function and craniofacial morphology. I. A cephalometric longitudinal analysis in the growing rat fed a soft diet. Eur J Orthod 7: 237-283, 1985.

19) Vandeberg, J.R., Buschang, P.H. and Hinton, R.J.: Craniofacial growth in growth hormone-deficient rats. Anat Rec A Discov Mol Cell Evol Biol 278: 561570, 2004.

20) Maki, K., Nishioka, T., Shioiri, E., Takahashi, T. and Kimura, M.: Effects of dietary consistency on the mandible of rats at the growth stage: computed $\mathrm{X}$-ray densitometric and cephalometric analysis. Angle Orthod 72: 468-475, 2002.

21) Nonaka, K., Yanagita, K., Matsumoto, T., Otani, H., Sasaki, Y. and Nakata, M.: Genetic study of mandibular size and shape in rats. Ped Dent J 1: 27-
35, 1991.

22) Dahlberg, G.: Statistical Methods for Medical and Biological Students. Allen \& Unwin, London, 1940, pp. 122-132.

23) Kamitani, Y., Maki, K., Tofani, I., Nishikawa, Y., Tsukamoto, K. and Kimura, M.: Effects of grape seed proanthocyanidins extract on mandibles in developing rats. Oral Dis 10: 27-31, 2004.

24) Vermeulen, A.: The metabolism of 4-14C prednisolone. J Endocrinol 18: 278-291, 1959.

25) Uribe, M., Schalm, S.W., Summerskill, W.H. and Go, V.L.: Oral prednisone for chronic active liver disease: dose responses and bioavailability studies. Gut 19: 1131-1135, 1978.

26) Weinstein, R.S., Jilka, R.L., Parfitt, A.M. and Manolagas, S.C.: Inhibition of osteoblastogenesis and promotion of apoptosis of osteoblasts and osteocytes by glucocorticoids. Potential mechanisms of their deleterious effects on bone. J Clin Invest $\mathbf{1 0 2}$. 274-282, 1998.

27) Iu, M.F., Kaji, H., Sowa, H., Naito, J., Sugimoto, T. and Chihara, K.: Dexamethasone suppresses Smad3 pathway in osteoblastic cells. J Endocrinol 185: 131138, 2005.

28) Hofbauer, L.C., Gori, F., Riggs, B.L., Lacey, D.L., Dunstan, C.R., Spelsberg, T.C. and Khosla, S.: Stimulation of osteoprotegerin ligand and inhibition of osteoprotegerin production by glucocorticoids in human osteoblastic lineage cells: potential paracrine mechanisms of glucocorticoid-induced osteoporosis. Endocrinology 140: 4382-4389, 1999.

29) Hoyte, D.A.: Mechanisms of growth in the cranial vault and base. J Dent Res 50: 1447-1461, 1971.

30) Babler, W.J., Persing, J.A., Nagorsky, M.J. and Jane, J.A.: Restricted growth at the frontonasal suture: alterations in craniofacial growth in rabbits. Am J Anat 178: 90-98, 1987.

31) Fujita, T., Ohtani, J., Shigekawa, M., Kawata, T., Kaku, M., Kohno, S., Tsutsui, K., Tenjo, K., Motokawa, M., Tohma, Y. and Tanne, K.: Effects of sex hormone disturbances on craniofacial growth in newborn mice. J Dent Res 83: 250-254, 2004.

32) Tanimoto, K., Imada, M., Ohno, S., Sasaki, A., Honda, K. and Tanne, K.: Association between craniofacial growth and urinary bone metabolic markers (pyridinoline, deoxypyridinoline) in growing rats. J Dent Res 82: 28-32, 2003.

33) Eratalay, Y.K., Simmons, D.J., El-Mofty, S.K., Rosenberg, G.D., Nelson, W., Haus, E. and Halberg, F.: Bone growth in the rat mandible following everyday or alternate-day methylprednisolone treatment schedules. Arch Oral Biol 26: 769-777, 1981.

34) Shibata, S., Suzuki, S., Tengan, T., Ishii, M. and Kuroda, T.: A histological study of the developing condylar cartilage of the fetal mouse mandible using coronal sections. Arch Oral Biol 41: 47-54, 1996.

35) Koedam, J.A., Smink, J.J. and van Buul-Offers, S.C.: Glucocorticoids inhibit vascular endothelial growth factor expression in growth plate chondrocytes. Mol Cell Endocrinol 197: 35-44, 2002. 
36) Klaus, G., Jux, C., Fernandez, P., Rodriguez, J., Himmele, R. and Mehls, O.: Suppression of growth plate chondrocyte proliferation by corticosteroids. Pediatr Nephrol 14: 612-615, 2000.

37) Jux, C., Leiber, K., Hugel, U., Blum, W., Ohlsson, C., Klaus, G. and Mehls, O.: Dexamethasone impairs growth hormone $(\mathrm{GH})$-stimulated growth by suppression of local insulin-like growth factor (IGF)-I production and expression of GH-and IGF-I-receptor in cultured rat chondrocytes. Endocrinology 139: 3296-3305, 1998.

38) Davidovitch, Z.: Radiographic and autoradiographic study on the effects of cortisone on bone growth in young albino rats. Arch Oral Biol 16: 897-914, 1971.

39) Delatte, M., Von den Hoff, J.W., Maltha, J.C. and Kuijpers-Jagtman, A.M.: Growth stimulation of mandibular condyles and femoral heads of newborn rats by IGF-I. Arch Oral Biol 49: 165-175, 2004.

40) Felts, W.J.: Transplantation studies of factors in skeletal organogenesis. I. The subcutaneously implanted immature long-bone of the rat and mouse. Am J Phys Anthropol 17: 201-215, 1959.

41) Meikle, M.C.: The role of the condyle in the postnatal growth of the mandible. Am J Orthod 4: 50-62, 1973.

42) Ferretti, J.L., Capozza, R.F. and Zanchetta, J.R.: Mechanical validation of a tomographic (pQCT) index for noninvasive estimation of rat femur bending strength. Bone 18: 97-102, 1996.

43) Komerik, N., Akkaya, A., Yildiz, M., Buyukkaplan, U.S. and Kuru, L.: Oral health in patients on inhaled corticosteroid treatment. Oral Dis 11: 303-308, 2005.

44) Wang, Y., Otsuka-Isoya, M., Shao, P., Sakamoto,
S. and Shinoda, H.: Effects of methylprednisolone on bone formation and resorption in rats. Jpn J Pharmacol 90: 236-246, 2002.

45) Dempster, D.W., Moonga, B.S., Stein, L.S., Horbert, W.R. and Antakly, T.: Glucocorticoids inhibit bone resorption by isolated rat osteoclasts by enhancing apoptosis. J Endocrinol 154: 397-406, 1997.

46) Albanese, C.V., Diessel, E. and Genant, H.K.: Clinical applications of body composition measurements using DXA. J Clin Densitom 6: 75-85, 2003.

47) Mushtaq, T. and Ahmed, S.F.: The impact of corticosteroids on growth and bone health. Arch Dis Child 87: 93-96, 2002.

48) Saag, K.G., Emkey, R., Schnitzer, T.J., Brown, J.P., Hawkins, F., Goemaere, S., Thamsborg, G., Liberman, U.A., Delmas, P.D., Malice, M.P., Czachur, M. and Daifotis, A.G.: Alendronate for the prevention and treatment of glucocorticoid-induced osteoporosis. Glucocorticoid-Induced Osteoporosis Intervention Study Group. N Engl J Med 339: 292-299, 1998.

49) Wallach, S., Cohen, S., Reid, D.M., Hughes, R.A., Hosking, D.J., Laan, R.F., Doherty, S.M., Maricic, M., Rosen, C., Brown, J., Barton, I. and Chines, A.A.: Effects of risedronate treatment on bone density and vertebral fracture in patients on corticosteroid therapy. Calcif Tissue Int 67: 277-285, 2000.

50) Adachi, J.D., Bensen, W.G., Brown, J., Hanley, D., Hodsman, A., Josse, R., Kendler, D.L., Lentle, B., Olszynski, W., Ste-Marie, L.G., Tenenhouse, A. and Chines, A.A.: Intermittent etidronate therapy to prevent corticosteroid-induced osteoporosis. $N$ Engl J Med 337: 382-387, 1997. 